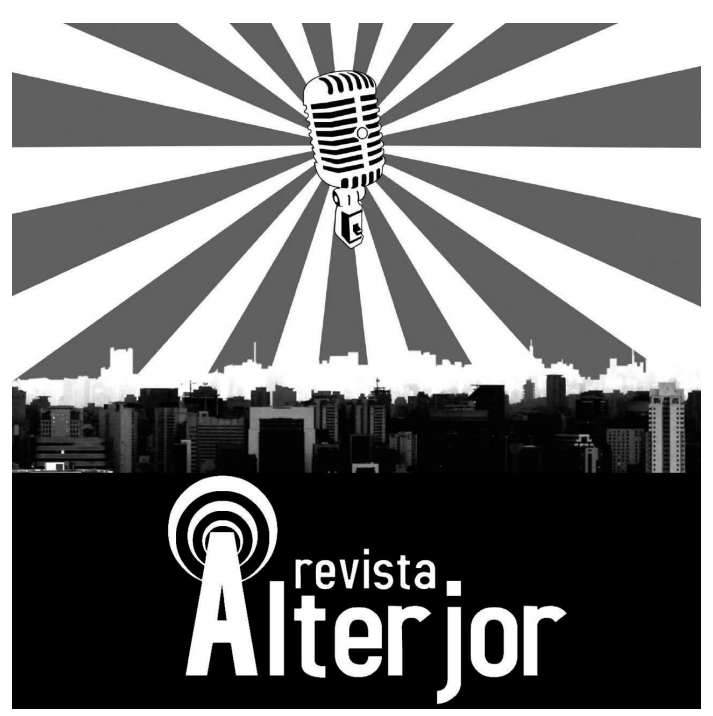

\title{
MÍDIA NINJA E A COMUNICAÇÃO CONTRA-HEGEMÔNICA
}

\author{
Ian Rebouças de Andrade ${ }^{1}$ \\ Márcia Vidal Nunes ${ }^{2}$
}

\begin{abstract}
RESUMO: A Mídia NINJA (Narrativas Independentes, Jornalismo e Ação) se propõe a fazer jornalismo, focando em narrativas do ponto de vista do ativista, militante, ou do popular, com objetivo de dar voz e visibilidade aos que não tem. A pergunta principal é: o coletivo Mídia Ninja se considera como uma comunicação contra-hegemônica? As metodologias utilizadas são entrevistas semiestruturadas e a observação participante. Algumas considerações são que: a Mídia Ninja e a mídia tradicional apresentam diferentes versões da realidade, ou diferentes enquadramentos e que para construir uma narrativa contrária e contra-hegemônica, tem que haver uma narrativa hegemônica para ser desmontada, sendo a relação entre a Mídia Ninja e a mídia tradicional dialógica e interdependente.
\end{abstract}

PAlAVRAS-CHAVE: Mídia Ninja. Mídia Alternativa. Hegemonia. Contra-Hegemonia. Teoria do Enquadramento.

ABSTRACT: The NINJA Media (Independent Narratives, Journalism and Action) proposes to do journalism, focusing on narratives from the point of view of the activist, activist, or the popular, with the objective of giving voice and visibility to those who do not have it. The main question is: the collective Mídia Ninja considers itself as a counter-hegemonic communication? The methodologies used are semi-structured interviews and participant observation. Some considerations are that the Ninja Media and the traditional media present different versions of reality, or different frameworks and that in order to build a contrary and counter-hegemonic narrative, there has to be a hegemonic narrative to be dismantled, being the relationship between the Ninja Media and the traditional dialogical and interdependent media.

KEYWORDS: Ninja Media. Alternative Media. Hegemony. Counter-Hegemony. Framework Theory.

\footnotetext{
Possui graduação em Comunicação Social - Publicidade e Propaganda pela Universidade de Fortaleza (2015) e mestrado em Sociologia pela Universidade Estadual do Ceará (2020). E-mail: iandeandradex@gmail.com

${ }^{2}$ Professora titular aposentada, atuando como professora do Programa de Pós-Graduação em Comunicação da Universidade Federal do Ceará, através do PROPAP/UFC (Programa Especial de Participação de Professores Aposentados da UFC). E-mail: marciavn@hotmail.com
}

\section{Revista ALTERJOR}

Grupo de Estudos Alterjor: Jornalismo Popular e Alternativo (ECA-USP)

Ano 11 - Volume 02 - Edição 24 - Julho-Dezembro de 2021

Av. Professor Lúcio Martins Rodrigues, 443, Cidade Universitária, São Paulo, CEP: 05508-020 


\section{Introdução}

A Mídia NINJA (Narrativas Independentes, Jornalismo e Ação), segmento importante do Coletivo Fora do Eixo (FDE), é uma rede de comunicação alternativa que se destacou no cenário político brasileiro e cearense, chamando atenção das mídias tradicionais (Rádio, TV e Jornais) através de mobilizações na conjuntura de crise na qual políticos foram expostos e julgados por crimes de corrupção.

Com origem em junho de 2011, por meio da mídia chamada "Pós-TV", e com popularização explodindo em junho de 2013 no Brasil, a mídia digital do Fora do Eixo, passou a desenvolver tecnologias de comunicação, além de atuar como um movimento social em rede em colaboração constante com outros grupos, coletivos e movimentos sociais que mantêm afinidades com suas lutas.

Já o Fora Do Eixo (FDE) é um coletivo que se autodenomina uma rede "ampla", "autônoma" e "descentralizada", que se articula em torno de produção cultural (através de festivais de música "autoral", alternativos aos esquemas das gravadoras), produção cinematográfica, publicitária e audiovisual (trabalhando para o segundo e terceiro setor) e mobilização política (notadamente na defesa de causas sociais, como a defesa dos direitos humanos, visibilidade e luta por direitos das minorias).

Neste trabalho, refletimos sobre o conceito de hegemonia segundo o pensamento do marxista italiano Antonio Gramsci (1968; 1980; 1999a ; 1999b ; 2001; 2011), em diálogo com autores nas áreas das Ciências Sociais e da Comunicação. Aproximamos a mídia tradicional (Rádio, TV e jornais) do conceito de hegemonia e a mídia alternativa emancipatória, neste caso específico, a Mídia Ninja, do conceito de contra-hegemonia. Também refletimos o papel da Mídia Ninja junto a grupos subalternos, contra as narrativas difundidas pelos veículos de comunicação tradicional e se a Ninja se considera como uma comunicação contra-hegemônica.

Clifford Geertz (1997) questiona o que é ser membro de um grupo a partir da própria visão do grupo: “como é seu modo de viver?" e "quais são precisamente os

\section{Revista ALTERJOR}

Grupo de Estudos Alterjor: Jornalismo Popular e Alternativo (ECA-USP)

Ano 11 - Volume 02 - Edição 24 - Julho-Dezembro de 2021 Av. Professor Lúcio Martins Rodrigues, 443, Cidade Universitária, São Paulo, CEP: 05508-020 


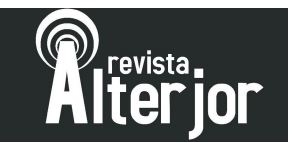

veículos através dos quais esta maneira de viver se manifesta?”. Geertz (1997) chega ao fim com a noção de que "eles" (neste caso específico deste trabalho, os membros da Mídia Ninja) consideram o "eu" como uma composição, uma persona, ou um ponto em uma estrutura. Este trabalho, então, é focado em como os membros do coletivo Mídia Ninja percebem o próprio coletivo.

Usamos a metodologia qualitativa, pois, segundo Minayo (2010), o método qualitativo é o que se aplica ao estudo da história, das relações, das representações, das crenças, das percepções, produtos das interpretações que os humanos fazem a respeito de como vivem, constroem seus artefatos e a si mesmos, sentem e pensam. As abordagens qualitativas se conformam melhor às investigações de grupos e segmentos delimitados e focalizados, de histórias sociais sob a ótica dos atores e de relações. Fazemos discussões entabuladas por contrapontos obtidos pela revisão de literatura, entrevistas semiestruturadas e observação participante no campo ${ }^{3}$ (GEERTZ, 1997) realizadas no decorrer do trabalho.

Trazemos algumas falas das entrevistas que foram realizadas nos dias 15 - 17 de fevereiro de 2019, no evento Feira ${ }^{4}$, realizado pelo Fora do Eixo com a Associação dos Produtores de Cultura do Ceará (PRODISC), no Centro Cultural Belchior e Centro Cultural Dragão do Mar, em Fortaleza, Ceará) com alguns dos membros e fundadores da Mídia Ninja e Fora do Eixo.

\footnotetext{
${ }^{3}$ Para realizar a pesquisa, precisamos ganhar a confiança e permissão do grupo, e fazer os indivíduos do coletivo compreenderem sua importância, elucidando nosso objetivo. Foram providenciados junto ao Comitê de Ética e Pesquisa da Universidade os pareceres necessários para a permissão e execução deste trabalho. A observação do coletivo ocorreu no período de 2016 a 2020. A entrada do pesquisador em campo se deu de maneira afetuosa com os membros pela afinidade política, o que também propiciou uma vivência como militante e membro na observação participante.

4 “A Feira, realizada desde 2002 pela Associação dos produtores de Cultura do Ceará (PRODISC), tem uma proposta voltada para as tecnologias de colaboração em rede e apresenta-se como espaço de convergência de interesses de forma democrática e criativa. [...] Enquanto sua programação de negócios e conhecimento sinalizam uma conexão entre agentes do hackerismo e do universo da música, o lado difusor da Feira está trazendo como referencial o feminino, suas mais amplas e múltiplas perspectivas, além da juventude negra, das periferias e dos grupos que seguem à margem". Disponível em: $<$ https://midianinja.org/news/mulheres-hackeiam-a-programacao-da-feira-2019-em-fortaleza/>. Acesso em: 02 jun. 2020.
}

\section{Revista ALTERJOR}

Grupo de Estudos Alterjor: Jornalismo Popular e Alternativo (ECA-USP)

Ano 11 - Volume 02 - Edição 24 - Julho-Dezembro de 2021 


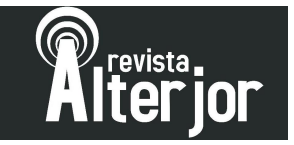

\section{O Conceito de Hegemonia em Gramsci}

No decorrer deste trabalho, das reflexões teóricas, das entrevistas com os Ninjas durante o trabalho de campo, surgiu a categoria Hegemonia. Aprofundamos o debate sobre o conceito de Hegemonia e de Contra-hegemonia, já que partimos da hipótese (pressuposto) que a comunicação do Ninja é uma comunicação alternativa contrahegemônica, como seus membros concordaram durante algumas entrevistas.

Gramsci (1980) constituiu uma influente fonte de reflexão sobre poder, capitalismo e cultura, oferecendo análises de sensibilidade e precisão notáveis. Gramsci (1980) desafia o domínio cultural, econômico, ideológico das classes dominantes com uma visão alternativa coerente e convincente a respeito de como a sociedade poderia se organizar.

O marxista italiano sustentava que, no decorrer dos séculos de sua expansão e consolidação, o capitalismo manteve e organizou sua liderança através de órgãos de informações e cultura, como escolas, universidades, igrejas, literatura, meios de comunicação e ideologias corporativas. As perspectivas sobre a sociedade mais ampla geradas no âmbito dessas instituições com frequência produziram, segundo o autor, uma visão de mundo inconteste, que adquiriu o status quo de inevitável, que o poder da classe dominante se assentava na habilidade singular, e por si só evidente, de dirigir a nação com sucesso.

As noções de contra-hegemonia e contra-hegemônico são bastante comuns entre os escritores influenciados pelo pensamento de Antonio Gramsci (1980) - embora o próprio não tenha utilizado exatamente esses termos em sua obra - como forma de categorizar as tentativas de contestar as estruturas ideológicas dominantes e suplantá-las com uma visão alternativa.

É preciso definir o que é hegemonia para então falar de contra-hegemonia. Segundo Eduardo Granja Coutinho (2014), em sua obra A comunicação do oprimido e outros ensaios, a hegemonia pode ser definida como a capacidade de um grupo social exercer sua liderança intelectual, moral e cultural sobre o conjunto da sociedade. A expressão Liderança intelectual nos lembra a seguinte citação de Antonio Gramsci (1968) na obra Os intelectuais e a organização da cultura:

\section{Revista ALTERJOR}

Grupo de Estudos Alterjor: Jornalismo Popular e Alternativo (ECA-USP)

Ano 11 - Volume 02 - Edição 24 - Julho-Dezembro de 2021 Av. Professor Lúcio Martins Rodrigues, 443, Cidade Universitária, São Paulo, CEP: 05508-020 
Cada grupo social, nascendo no terreno originário de uma função essencial no mundo da produção econômica, cria para si, ao mesmo tempo, de um modo orgânico, uma ou mais camadas de intelectuais que lhe dão homogeneidade e consciência da própria função, não apenas no campo econômico, mas também no campo social e político (GRAMSCI, 1968, p. 3)

Compreendendo a hegemonia como direção política e cultural, para Coutinho e Teixeira (2003), ela condiz com a obtenção de consenso para um universo de valores, de normas morais, de regras de conduta. A conquista se dá pelo consenso, que não opera só sobre a estrutura política, mas sobre o modo de pensar, sobre as orientações ideológicas. Para Antonio Gramsci (2011):

O critério metodológico sobre o qual se deve basear a análise é o seguinte: a supremacia de um grupo social se manifesta de dois modos, como "domínio" e como "direção intelectual e moral". Um grupo social domina os grupos adversários, que visa a "liquidar" ou submeter inclusive com a força armada, e dirige os grupos afins e aliados. Um grupo social pode e, aliás, deve ser dirigente já antes de conquistar o poder governamental (esta é uma das condições principais para a própria conquista do poder); depois, quando exerce o poder e mesmo se o mantém fortemente nas mãos, torna-se dominante, mas deve continuar a ser também "dirigente" (GRAMSCI, 2011, p. 290)

Gramsci (1980), em Maquiavel, a Política e o Estado Moderno, trabalha melhor sobre a direção política: quando um grupo social fundamental é dirigente sobre uma série de grupos dirigidos e subordinados, "o Estado é concebido como organismo próprio de um grupo, destinado a criar as condições favoráveis à expansão máxima desse grupo" (idem, 1980, p. 50). Com isso, Gramsci (1980) quer dizer que o grupo no poder molda o Estado para ele especificamente, e que isso significa uma hegemonia cultural, ideológica sobre o grupo subordinado. Luciano Gruppi (1978, p.11) auxilia essa compreensão, quando diz que "a hegemonia é entendida não apenas como direção política, mas também como direção moral, cultural e ideológica".

A chave para compreender o que diz Antonio Gramsci (1980) é a relação dialética entre estrutura e superestrutura. Estrutura é a base material das relações de produção, a

\section{Revista ALTERJOR}

Grupo de Estudos Alterjor: Jornalismo Popular e Alternativo (ECA-USP)

Ano 11 - Volume 02 - Edição 24 - Julho-Dezembro de 2021 Av. Professor Lúcio Martins Rodrigues, 443, Cidade Universitária, São Paulo, CEP: 05508-020 


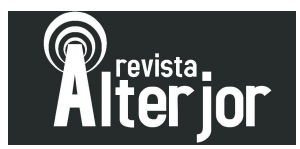

base da produção de riquezas, ou seja, o econômico. Já a Superestrutura é o modo de pensar e agir ( práxis $^{5}$ ), as esferas da política, da cultura, da ética, da moral, da ideologia.

Os elementos da política, segundo Gramsci (1980), são os pilares de qualquer ação coletiva. O primeiro elemento seria a existência real de dirigentes e dirigidos. A partir disso, o autor reflete sobre como preparar os dirigentes, identificar as linhas de menor resistência, alcançar a obediência de dirigidos e governados. Eduardo Granja Coutinho (2014) retoma Gramsci (1999a), ao dizer que para uma classe estar no poder não basta ser dominante (na esfera econômica), mas precisa ser dirigente também no campo das ideias.

\section{Mídia Ninja e a comunicação contra-hegemônica}

Então, como a comunicação influencia na formação da hegemonia? A linguagem, para Antonio Gramsci (1999a, p. 398), significa também cultura e filosofia, e, como tal, constitui um campo de força onde entram em disputa os interesses de diferentes grupos sociais. A linguagem é, na realidade, uma multiplicidade de fatos mais ou menos organicamente coerentes e coordenados: pode-se dizer que uma linguagem pessoal e própria traduz um modo pessoal de pensar e sentir (idem, 1999a, p.398).

Nesse campo de força ideológico, os subalternos adquirem consciência de sua posição e luta. Nele, as classes e frações de classes esforçam-se para impor sua visão de mundo e contar a história a partir de sua perspectiva:

[...] [uma das potencialidades da Mídia Ninja é] poder tá contando as histórias em primeira pessoa, as histórias que ele [o invisibilizado] acredita. [...] Ele tem contato com uma série de repertórios que são oferecidos a ele permanentemente, ele conhece muita gente também que tá transitando nos lugares onde ele, ele gostaria de tá, e ele tem contato direto com causas, temas e iniciativas que impactam bastante na sua própria vida [...] numa ocupação de sem teto, num assentamento sem-terra, numa aldeia indígena, [...] num coletivo trans, num coletivo feminista, num movimento negro, todo esse contato direto com essas iniciativas são muito transformadoras (PABLO CAPILÉ ${ }^{6}, 2019$ )

\footnotetext{
${ }^{5}$ Entendemos práxis como uma relação dialética entre a teoria e a prática.

${ }^{6}$ Entrevista concedida ao autor por Pablo Capilé em 2019.
}

\section{Revista ALTERJOR}

Grupo de Estudos Alterjor: Jornalismo Popular e Alternativo (ECA-USP)

Ano 11 - Volume 02 - Edição 24 - Julho-Dezembro de 2021 


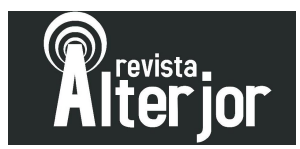

Ao valorizar a poesia, fala oral, cantos, histórias, narrativas, uma nova comunicação pode ser construída: uma comunicação alternativa. Nesse sentido, a Mídia Ninja, objeto empírico deste estudo, colabora para classes ou grupos subalternos contarem suas histórias, como aponta Raíssa Galvão ${ }^{7}$ (2019), membro deste coletivo:

[...] se a gente vai pra um ato, pra alguma ação [...] a gente não necessariamente quer mostrar os dois lados, ou três, ou quantos lados tiver. A gente quer mostrar o lado de quem não tem voz naturalmente. Então o nosso objetivo é dar voz e visibilidade pra grupos vulnerabilizados pela sociedade no geral, que sofrem seja com racismo, com [...] LGBTfobia [...] (RAÍSSA GALVÃO, 2019, GRIFOS NOSSOS)

Por "grupos vulnerabilizados", Raíssa ${ }^{8}$ se refere aos grupos que sofrem preconceitos, que estão à margem da sociedade, expostos a riscos por contextos sociais e econômicos. O objetivo da Mídia Ninja, segundo ela, é dar voz, visibilidade para esses grupos e também tem uma contribuição importante de informação, para o combate aos preconceitos (racismo, LGBTfobia, por exemplo) e sua disseminação.

Gramsci (1999a) sustenta que a direção político-cultural dos estratos dirigentes envolve o empobrecimento, a fragmentação, o esvaziamento da linguagem (consciência popular) e do sentido de consciência de classe. Portanto, a organização de uma cultura contra-hegemônica implica o desenvolvimento da auto expressão (e também da comunicação) das camadas subalternas.

A visibilidade se dá por meio da qual se expressam a voz e o conteúdo revolucionários. Seja pela aquisição de novos meios de expressão e de comunicação, seja pela elaboração de novos matizes de significados.

[Mídia Ninja é] contra hegemônica e ao mesmo tempo tem duas frentes assim, tem a desconstrução da narrativa oficial, que seria essa lógica mais contra hegemônica, e tem também a da visibilidade, para temas que a narrativa oficial ignora completamente, que estaria numa lógica mais propositiva, assim, não necessariamente só de contrapor a alguma coisa, mas de propor novos modelos, por exemplo, de vida, de economia, de saúde, tudo isso. Eu acho que a Mídia Ninja é formada

\footnotetext{
${ }^{7}$ Entrevista concedida ao autor por Raíssa Galvão em 2019.

${ }^{8}$ Idem.
}

\section{Revista ALTERJOR}

Grupo de Estudos Alterjor: Jornalismo Popular e Alternativo (ECA-USP)

Ano 11 - Volume 02 - Edição 24 - Julho-Dezembro de 2021 
por essas pessoas... as pessoas fazem parte da Mídia Ninja, elas colaboram ativamente, elas não são alguém do qual a gente está falando sobre, elas estão falando sobre elas dentro da Mídia Ninja. Elas não estão sendo tratadas como objetos dentro dum processo narrativo, elas são sujeitos e ativos [...], é a própria voz delas que na verdade tá sendo construída dentro, a gente trabalha sempre o empoderamento de novas lideranças, de novas iniciativas, coletivos. [A] transferência da tecnologia radical do que a gente desenvolveu pra que cada um tenha o seu próprio processo de autonomia narrativa, que não seja, a gente não é o fornecedor de autonomia pra ninguém ou não é o fornecedor de narrativa, na verdade a gente é o fornecedor de tecnologia pra que qualquer um possa fazer isso, assim, qualquer um possa ser Ninja, qualquer um possa criar seu coletivo e fazer exatamente isso que a gente já faz sem necessariamente ter que se chamar assim (RAFAEL VILELA $^{9}, 2019$, GRIFOS NOSSOS)

A potencialidade das reflexões de Gramsci (1980) sobre a comunicação consiste justamente em relacioná-la com a totalidade da vida social, compreendendo-a como cultura, práxis interativa, mediação entre sujeito e objeto e sujeito e sujeito. E, assim, está associada à problemática do Estado, das relações de poder, da hegemonia, isto é, da liderança intelectual e moral de um grupo social sobre o conjunto da sociedade.

Assim, todo processo de hegemonia é, necessariamente, um processo comunicacional. Pois é pela interação, pela reelaboração e pelo compartilhamento de signos, que os sujeitos constroem suas identidades, organizam sua visão de mundo, representando a realidade a partir de uma determinada perspectiva e de acordo com seus interesses, anseios e expectativas. Pela comunicação mostram-se as ideologias que agem ética e politicamente na mudança social na história:

Eu acho que a conjuntura tem, é determinante na definição das pautas por um lado... né, tem uma camada do que a gente faz que tá muito pautada pela conjuntura. Agora tem uma outra camada que independe da conjuntura, são as ações de propostas, propositivas, [o evento] "a Feira", por exemplo, aqui que a gente tá acompanhando ela não é uma reação à conjuntura... ela é uma proposta de um modelo de organização de troca, de conhecimento, de uma forma de ver a sociedade. Então aqui é um exemplo muito legal disso, assim, de que a gente não tá aqui só reagindo ao Bolsonaro, por exemplo, que aí é onde a gente se encontra com a grande imprensa, porque toda imprensa reage à

\footnotetext{
${ }^{9}$ Entrevista concedida ao autor por Rafael Vilela em 2019.
}

\section{Revista ALTERJOR}


conjuntura, a gente também, como imprensa. Agora como Movimento a gente se sente na obrigação de não só reagir à conjuntura, mas também propor novas possibilidades pra conjuntura. Que é o tal do Ninja ser narrativas independentes, jornalismo e a ação [...]. Essa "ação" no final ele tá ligado a isso, a gente não precisa esperar uma coisa acontecer pra gente contar uma história daquilo, a gente pode criar uma história e contar a história daquilo. Isso é uma diferença bem marcante da Mídia Ninja com os veículos de imprensa tradicional que ainda hoje defende aquela velha ideia de isonomia ${ }^{10}$, de isenção, de você não tomar um lado, que é uma coisa que a gente absolutamente não acredita (RAFAEL VILELA ${ }^{11}, 2019$, GRIFOS NOSSOS)

A disputa pela hegemonia, é também disputa pela criação e difusão de uma determinada concepção de mundo, tendo como objetivo a conservação ou transformação da estrutura socioeconômica, a "construção de um universo intersubjetivo de crenças e valores", como disse Carlos Nelson Coutinho (1992, p. 67-68).

A questão política baseia-se na existência de governantes e governados, dirigentes e dirigidos (GRAMSCI, 1999b, p. 325). A hegemonia é obtida e consolidada em embates que comportam não apenas questões vinculadas à estrutura econômica e à organização política, mas também envolvem, no plano ético-cultural, a expressão de saberes, práticas, modos de representação e modelos de autoridade que o Estado burguês quer legitimar e universalizar (MORAES, 2010).

Historicamente, o poder exercido pelos governantes conjugou força e persuasão, coerção e consenso. Nicolau Maquiavel na obra O Príncipe (2010, p. 27-28) afirmou que o príncipe que quisesse garantir a estabilidade do Estado deveria considerar que "a natureza dos povos é variável; e, se é fácil persuadi-los de uma coisa, é difícil firmá-los nessa persuasão. Por isso convém estar ordenado de modo que, quando já não acreditarem, seja possível fazê-los crer à força".

\footnotetext{
${ }^{10} \mathrm{O}$ princípio da isonomia encontra-se previsto em nossa Carta Magna como um dos direitos fundamentais dos cidadãos, alcançado por relevante esforço daqueles que, anos e anos atrás lutaram em busca da igualdade e da aplicação da verdadeira democracia preconizada no Estado Democrático de Direito. O artigo $5^{\circ}$, caput, da Constituição Federal vigente diz que: "Todos são iguais perante a Lei sem distinção de qualquer natureza, garantindo-se aos brasileiros e aos estrangeiros residentes no País a inviolabilidade do direito à vida, à liberdade, à igualdade, à segurança e à propriedade, nos termos seguintes(...)" (BRASIL, [1988] 2017).

${ }^{11}$ Entrevista concedida ao autor por Rafael Vilela em 2019.
}

\section{Revista ALTERJOR}

Grupo de Estudos Alterjor: Jornalismo Popular e Alternativo (ECA-USP)

Ano 11 - Volume 02 - Edição 24 - Julho-Dezembro de 2021 


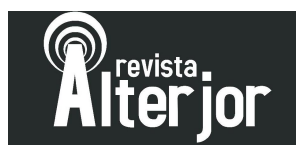

Essa ideia de crença, pode ser entendida como ideologia - as ideias particulares da classe dominante de uma época apresentadas misticamente como ideias absolutas universais - e essa "força" como os mecanismos de coerção e dominação direta - a burocracia, os aparatos policiais-militares, o aparato jurídico etc. - que constituem o poder do Estado, por meio do qual, a classe economicamente dominante se torna também política e ideologicamente dominante.

Ocupando um lugar de destaque na sociedade civil, a mídia é uma das fortificações importantes que protegem/amortecem o aparelho do Estado do impacto das crises político-econômicas. A despeito da insatisfação existente na sociedade global, das periódicas crises financeiras e políticas que afetam o planeta, aumentando o fosso entre os ricos e os miseráveis, a mídia hegemônica contribui para o consenso necessário à supremacia do capital, como diz Coutinho (2014).

O jornalismo deve ser um veículo de informação para equipar os cidadãos com as ferramentas vitais: "ao exercício dos seus direitos e voz na expressão das suas preocupações - designado como a liberdade positiva do jornalismo" (TRAQUINA, 2005, p. 129). Assim, a imprensa atuaria como um elo indispensável entre a opinião pública e as instituições governantes. Como é sabido, a mídia tradicional não tem se preocupado em fornecer informações para equipar os cidadãos com ferramentas para o exercício de cidadania.

Aqui o conceito de opinião pública em Gramsci revela-se fundamental para a discussão. Esse termo é citado por Gramsci (1999b) numa das definições de hegemonia nos Cadernos do Cárcere vol.3:

O exercício "normal" da hegemonia, no terreno tornado clássico do regime parlamentar, caracteriza-se pela combinação da força e do consenso, que se equilibram de modo variado, sem que a força suplante em muito o consenso, mas, ao contrário, tentando fazer com que a força pareça apoiada no consenso da maioria, expresso pelos chamados órgãos de opinião pública - jornais e associações -, os quais, por isso, em certas situações, são artificialmente multiplicados (GRAMSCI, 1999B, p. 95, GRIFOS NOSSOS).

\section{Revista ALTERJOR}

Grupo de Estudos Alterjor: Jornalismo Popular e Alternativo (ECA-USP)

Ano 11 - Volume 02 - Edição 24 - Julho-Dezembro de 2021 Av. Professor Lúcio Martins Rodrigues, 443, Cidade Universitária, São Paulo, CEP: 05508-020 


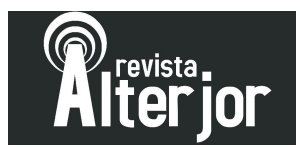

A partir da perspectiva que órgãos de opinião pública - "jornais e associações”, nas palavras de Gramsci (1999b), têm importância para manutenção de um consenso, a grande mídia mostra um enquadramento da realidade.

\section{Mídia Ninja e o enquadramento da realidade}

Para Rafael Vilela ${ }^{12}$, uma comunicação contra-hegemônica é pautada no enquadramento diferenciado da mídia hegemônica:

Tem a desconstrução da narrativa oficial, que seria essa lógica mais contra hegemônica, e tem também a da visibilidade, pra temas que a narrativa oficial ignora completamente, que estaria numa lógica mais propositiva, assim, não necessariamente só de contrapor a alguma coisa, mas de propor novos modelos, por exemplo, de vida, de economia, de saúde, tudo isso (RAFAEL VILELA ${ }^{13}, 2019$ )

Para Carlos Alberto de Carvalho (2009), o conceito de enquadramento (framing) vem das teorias da comunicação e se apoia em que a mídia utiliza de certas palavras, ideias, expressões e adjetivos que promovem uma abordagem que molda o acontecimento, destacando alguns aspectos e ocultando outros. Assim, recorta-se determinado ângulo do fato (ou quadro/moldura) do problema tratado, tornando-o mais conhecido, e, portanto, mais "real", condicionando a atitude dos cidadãos em relação ao ocorrido e, eventualmente, interferindo nos processos de mudanças sociais.

Através da análise e do olhar crítico sob o enquadramento utilizado por um veículo de mídia pode-se perceber sua linha editorial e os interesses que defende. A Mídia Ninja encontra-se também dentro dessa lógica. De modo geral, o enquadramento diz respeito à forma como uma dada situação é apresentada e interpretada para e pelo interlocutor, determinando assim a sua capacidade de, frente ao acontecimento, responder à seguinte pergunta: o que está acontecendo aqui?

\footnotetext{
${ }^{12}$ Entrevista concedida ao autor por Rafael Vilela em 2019.

${ }^{13}$ Idem.
}

\section{Revista ALTERJOR}

Grupo de Estudos Alterjor: Jornalismo Popular e Alternativo (ECA-USP)

Ano 11 - Volume 02 - Edição 24 - Julho-Dezembro de 2021 


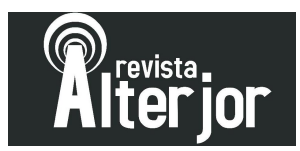

A maneira como as informações são apresentadas pode influenciar diretamente o modo como as pessoas entendem essa informação. A mídia tradicional, e também a alternativa influem diretamente no modo de interpretação das pessoas, construindo a mensagem, de modo a deixar margem para uma única maneira de interpretá-la. Por exemplo: diante de um fato apresentado na televisão é desejado e necessário que os leitores ou telespectadores compreendam a informação.

Para que isso aconteça, no entanto, essa informação nova precisa ser ligada a outras já conhecidas do telespectador ou do leitor - isto é, como Martino (2014, p. 46) diz, essa informação deve ser enquadrada (framed) na moldura de referências (ou repertórios) anteriores, um contexto. No entanto, há um efeito colateral: esse contexto passa a dar o sentido da notícia e determina a compreensão do fato noticiado dentro dessa moldura (frame).

Privilegiar os quadros de referência da atividade jornalística, em detrimento dos quadros de referência naturais, e especialmente os sociais, realça, em demasia, as práticas jornalísticas como autônomas relativamente ao restante do mundo social. O jornalismo como prática institucionalizada, os constrangimentos organizacionais daí derivados, a visão dos jornalistas sobre o que é notícia - resultado da perspectiva que eles têm sobre a própria profissão - e a tendência que as notícias têm de privilegiar posições ideológicas hegemônicas, reforçando a manutenção do status quo, dentre outros fatores, são fundamentais para uma compreensão dos modos como são promovidos os enquadramentos (CARVALHO, 2009, P. 4).

Assim, narrar um acontecimento transformado em notícia, dando-lhe um enquadramento, consiste, à primeira vista, na seleção de aspectos que dão à narrativa sobre ele inteligibilidade, a partir de estruturas cognitivas e quadros de referência que conduzirão a uma determinada visão, dentre uma série de outras possíveis, relativamente ao que é apresentado ao fruidor da informação daí resultante.

Gramsci (1980) pode ser utilizado para complementar essa discussão, quando diz que a imprensa "supostamente apolítica" é como um partido que determina a agenda política e pública. Assim, Gramsci (1980) contribui também para a reflexão sobre a finalidade política da imprensa. Uma pergunta surge: of framing, ou enquadramento, teria

\section{Revista ALTERJOR}

Grupo de Estudos Alterjor: Jornalismo Popular e Alternativo (ECA-USP)

Ano 11 - Volume 02 - Edição 24 - Julho-Dezembro de 2021 Av. Professor Lúcio Martins Rodrigues, 443, Cidade Universitária, São Paulo, CEP: 05508-020 


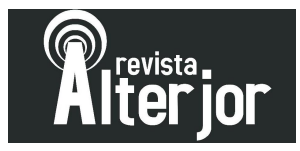

então uma finalidade política? No entendimento de Gramsci (1980) sim. O italiano traz hipóteses que podem ser aplicadas até hoje na realidade de muitos países e como a mídia pode trabalhar (a favor das classes dirigentes), para contribuir na formação de uma massa de manobra:

[...] a massa é simplesmente de "manobra" e é "conquistada" com pregações morais, estímulos sentimentais, mitos messiânicos de expectativa de idades fabulosas, nas quais todas as contradições e misérias do presente serão automaticamente resolvidas e sanadas (GRAMSCI, 1980, p.24, GRIFOS NOSSO)

Na mídia sensacionalista de seu tempo, Gramsci (2001) identificou aquela característica que seria uma das principais: espetacularização ou estetização da política. $\mathrm{Ou}$, em seus termos, a redução das "questões gerais e de princípios" a "passatempos literários e artísticos” (GRAMSCI, 2001, p. 112). Esse seria o papel da mídia hegemônica: assimilar e esvaziar tais questões de seu conteúdo histórico, atribuindo-lhes novos significados e signos com função apaziguadora, impedindo assim que o povo se reconheça como sujeito, ou como protagonista, de sua história:

O interesse do público é desviado: de parte em causa, o público se torna mero 'espectador' de uma luta de gladiadores, que aguarda 'belos golpes' em si e por si: a política, a literatura, a ciência, são degradadas a uma competição 'esportiva'. Por isso é preciso [...] levar o público a perceber que de te fabula narratur [a história é sobre você] (GRAMSCI, 2001, p. 112)

A opinião pública é expressa pelos órgãos formadores de opinião (que utilizam o frame), legitima e dá sustentação à ação coercitiva do Estado, o qual "quando iniciar uma ação pouco popular, cria preventivamente a opinião pública adequada, ou seja organiza e centraliza certos elementos da sociedade civil” (GRAMSCI, 1999b, p. 265).

Isso explica como a grande mídia comercial influencia na formação da opinião pública na concepção do que seria uma causa polêmica ou uma causa "de esquerda" ou de "direita", esvaziando ou generalizando esses sentidos. Um exemplo ilustrativo aconteceu durante as manifestações de junho de 2013, quando a TV Globo noticiou,

\section{Revista ALTERJOR}

Grupo de Estudos Alterjor: Jornalismo Popular e Alternativo (ECA-USP)

Ano 11 - Volume 02 - Edição 24 - Julho-Dezembro de 2021 Av. Professor Lúcio Martins Rodrigues, 443, Cidade Universitária, São Paulo, CEP: 05508-020 


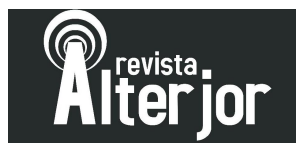

criminalizando os manifestantes, usando a denominação de vândalos, ao mostrar somente um enquadramento (frame) do fato, criando uma justificativa, assim, para a operação de coerção policial, com bombas de efeito moral e balas de borracha naquele dia ${ }^{14}$.

Se os veículos de comunicação estão aparelhados ideológica e economicamente pelos interesses das instituições privadas e do Estado, que não têm interesse na formação cidadã dos dirigidos, nesse sentido, o intelectual orgânico, tal como Gramsci (1980) concebe, é o representante ou porta voz de sua classe econômica e social e tem papel fundamental na sua classe. É importante destacar que o intelectual orgânico pode trabalhar a favor da classe dirigente, ou a favor da classe subalterna.

John Downing (2004), na obra Mídia Radical, diz que os comunicadores intelectuais e ativistas se integram organicamente com as classes trabalhadoras para o desenvolvimento de uma nova ordem social justa e culturalmente superior, ao contrário dos intelectuais organicamente integrados com as classes dominantes, cujos esforços comunicativos fortaleceram a hegemonia do capital.

A noção de contra-hegemonia é concebida como forma de categorizar as tentativas de contestar as estruturas ideológicas dominantes e suplantá-las com uma visão alternativa como explicado. Segundo Downing (2004), muitos meios de comunicação alternativos pertencem a esse modelo de contra-hegemonia (mas nem todos). A proliferação dessa mídia seria vital, tanto para gerar alternativas no debate público como para limitar qualquer tendência da liderança oposicionista, seja qual for a forma que ela assume, de se radicalizar como agência de dominação em vez de liberdade.

O coletivo Mídia Ninja nasceu como uma forma alternativa de fazer cultura, produzindo eventos e atos culturais com bandas musicais, festivais alternativos aos esquemas de gravadoras e do mercado tradicional capitalista no Brasil. No entanto, reproduzem organogramas das redações de veículos de comunicação convencionais, de jornais tradicionais e mercadológicos, com gatekeepings (porteiro das informações), fact

\footnotetext{
14 "Vândalos destroem patrimônio público do Rio de Janeiro. Manifestantes também tentaram invadir a prefeitura da cidade. Depois dos protestos, 62 pessoas deram entrada em um hospital”. Disponível em: < http://g1.globo.com/jornal-hoje/noticia/2013/06/vandalos-destroem-patrimonio-publico-do-rio-dejaneiro.html > Acesso em: 24 de junho de 2019.
}

\section{Revista ALTERJOR}

Grupo de Estudos Alterjor: Jornalismo Popular e Alternativo (ECA-USP)

Ano 11 - Volume 02 - Edição 24 - Julho-Dezembro de 2021 


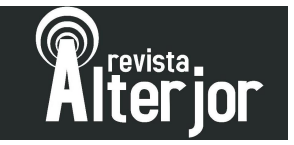

checking (checagem de fatos), editores, redatores, diagramadores, designers, fotógrafos, repórteres, etc.

Por fim, para Moraes (2010), um dos desafios centrais para o pensamento contrahegemônico e emancipatório consiste em alargar a visibilidade pública de enfoques ideológicos que contribuam para a reorganização de repertórios, princípios, e variáveis de identificação e coesão, com vistas à alteração gradual e permanente das relações sociais e de poder. Para isso, são fundamentais campanhas, mobilizações e pressões sociais por legislações que detenham a forte concentração do setor nas mãos de um reduzido número de corporações multimídias, por isso também é fundamental a existência de outras maneiras de fazer, divulgar e ver cultura.

\section{CONSIDERAÇÕES FINAIS}

A Mídia Ninja apresenta coberturas focadas na visão do militante, do ativista, do manifestante, dos populares, enquanto a mídia tradicional foca em outro tipo de cobertura, muitas vezes sem ter o devido respeito humano. Sendo assim, o que a Mídia Ninja e a mídia tradicional apresentam são diferentes versões da realidade, ou seja, diferentes enquadramentos.

A Mídia Ninja colabora para pontos de resistência aos discursos hegemônicos (trazidos pela mídia tradicional), que abrem horizontes de irradiação: utilização de tecnologias digitais, meios, redes, suportes, softwares livres e plataformas que se apropriam de ferramentas tecnológicas, para disseminar informações e ideias que valorizam a consciência social, as causas comunitárias e os direitos sociais. Para seus membros, o objetivo da Mídia Ninja é mostrar narrativas dos excluídos e invisibilizados pela mídia tradicional. Para que uma mídia seja alternativa e emancipatória, deve apresentar um discurso não alinhado à ideologia hegemônica, constituir-se em uma ação de contra-hegemonia. Sendo assim, o discurso da mídia alternativa emancipatória deve ser, em resumo, crítico, questionador, problematizador, processual e transformador.

A Mídia Ninja constrói uma narrativa jornalística que também envolve um trabalho de representação importante de si mesmos e do modo como enxergam o mundo, os outros e os acontecimentos que são pautados. A mídia tradicional mostra-se elemento

\section{Revista ALTERJOR}

Grupo de Estudos Alterjor: Jornalismo Popular e Alternativo (ECA-USP)

Ano 11 - Volume 02 - Edição 24 - Julho-Dezembro de 2021 Av. Professor Lúcio Martins Rodrigues, 443, Cidade Universitária, São Paulo, CEP: 05508-020 


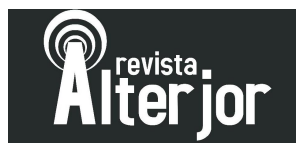

importante para moldar o que é a mídia alternativa, o que são as manifestações e quem são os que fazem parte disso, criando um imaginário social a partir de uma narrativa hegemônica. As noções de subalternidade e de contra-hegemonia revelam-se importantes para entender a atuação do Mídia Ninja no Brasil e as causas que defende, ao que ela resiste, ao que se opõe e como ela pensa e enxerga a conjuntura e outros muitos temas. Para construir uma narrativa contrária e contra-hegemônica, tem que haver uma narrativa hegemônica para ser desmontada. Assim, a relação entre a Mídia Ninja e a mídia tradicional é dialógica e interdependente.

Os cidadãos da era da informação se envolvem na produção de mensagens nesses novos meios de comunicação de massa, desenvolvendo redes de comunicação, se tornando capazes de inventar novos programas para suas vidas com as matérias primas de seu sofrimento, seus medos, seus sonhos, seus anseios de mudança e esperanças. Elaboram seus projetos, compartilhando sua experiência. Subvertem a prática da comunicação, tal como usualmente se dá, ocupando o veículo e criando a mensagem. Pessoas podem desafiar a dominação e a hegemonia, conectando-se entre si, compartilhado sua indignação, sentindo o companheirismo, montando projetos coletivos e construindo projetos alternativos para si próprias e para a sociedade como um todo.

\section{REFERÊNCIAS BIBLIOGRÁFICAS}

BRASIL. Constituição (1988). Constituição da República Federativa do Brasil de 1988. 52. ed. Brasília: Câmara dos Deputados, Edições Câmara, 2017. 116p.

CARVALHO, Carlos Alberto de. O enquadramento como conceito desafiador à compreensão do jornalismo. In: XIV CONGRESSO DE CIÊNCIAS DA COMUNICAÇÃO NA REGIÃO SUDESTE, 14., 2009. Rio de Janeiro, Anais... Rio de Janeiro: [s.n.], 2009

COUTINHO, Carlos Nelson. Gramsci: um estudo sobre seu pensamento político. 2. ed. Rio de Janeiro: Campus, 1992.

COUTINHO, Carlos Nelson; TEIXEIRA, Andréa de Paula. Ler Gramsci, entender a realidade. Organização e apresentação Carlos Nelson Coutinho, Andréa de Paula Teixeira. Rio de Janeiro: Civilização Brasileira, 2003.

\section{Revista ALTERJOR}

Grupo de Estudos Alterjor: Jornalismo Popular e Alternativo (ECA-USP)

Ano 11 - Volume 02 - Edição 24 - Julho-Dezembro de 2021 Av. Professor Lúcio Martins Rodrigues, 443, Cidade Universitária, São Paulo, CEP: 05508-020 


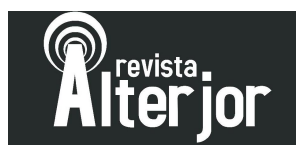

COUTINHO, Eduardo Granja. A comunicação do oprimido e outros ensaios. Rio de Janeiro: Mórula, 2014.

DOWNING, John D. H. Mídia Radical: rebeldia nas comunicações e movimentos sociais. John D. H. Downing com a colab. de Tamara Villarreal Ford, Genève Gil, Laura Stein; Tradução de Silvana Vieira. 2. ed. São Paulo: Senac de São Paulo, 2004

GEERTZ, Clifford. Do ponto de vista dos nativos: a natureza do entendimento antropológico. In: GEERTZ, Clifford. O Saber Local. Petrópolis: Vozes, 1997

GRAMSCI, Antonio. Cadernos do cárcere. Edição e tradução de Carlos Nelson Coutinho. Rio de Janeiro: Civilização Brasileira, 1999b. vol. 3.

GRAMSCI, Antonio. Cadernos do cárcere. Edição e tradução de Carlos Nelson Coutinho. Rio de Janeiro: Civilização Brasileira, 2001. vol. 4.

GRAMSCI, Antonio. Cadernos do cárcere. Edição e tradução de Carlos Nelson Coutinho. Rio de Janeiro: Civilização Brasileira, 1999a. vol. 1.

GRAMSCI, Antonio. Hegemonia, Guerra de Movimento, Guerra de Posição. In: COUTINHO, Carlos Nelson. (ORG.) O Leitor de Gramsci: escritos escolhidos 19161935. Rio de Janeiro: Civilização Brasileira, 2011

GRAMSCI, Antonio. Maquiavel, a política e o Estado Moderno. Tradução de Luiz Mário Gazzaneo. 4a Edição. Rio de Janeiro: Civilização brasileira, 1980

GRAMSCI, Antonio. Os intelectuais e a organização da Cultura. Tradução de Carlos Nelson Coutinho. Rio de Janeiro: Civilização Brasileira, 1968

GRUPPI, Luciano. Conceito de Hegemonia em Gramsci. Tradução de Carlos Nelson Coutinho. Apresentação de Luiz Werneck Vianna. Rio de Janeiro: Edições Graal, 1978

MAQUIAVEL, Nicolau. O Príncipe. Tradução de Maria Júlia Goldwasser; Revisão da tradução Zelia de Almeida Cardoso. 4. ed. São Paulo: WMF Martins Fontes, 2010.

MARTINO, Luís Mauro Sá. Teoria da comunicação: ideias, conceitos e métodos. 5. ed. Petrópolis, RJ: Vozes, 2014. p. 46-49

MINAYO, Maria Cecília de Souza. O desafio do conhecimento: pesquisa qualitativa em saúde. 12. ed. São Paulo: Hucitec, 2010

MORAES, Dênis de. Comunicação, Hegemonia E Contra-hegemonia: A Contribuição Teórica De Gramsci. Revista Debates, Porto Alegre, v.4, n.1, p. 54-77, jan.-jun, 2010.

TRAQUINA, Nelson. Teorias do Jornalismo, porque as notícias são como são. 2. ed. Florianópolis: Insular, 2005, 224 p.

Revista ALTERJOR

Grupo de Estudos Alterjor: Jornalismo Popular e Alternativo (ECA-USP)

Ano 11 - Volume 02 - Edição 24 - Julho-Dezembro de 2021 Av. Professor Lúcio Martins Rodrigues, 443, Cidade Universitária, São Paulo, CEP: 05508-020 